\title{
A blind area of family planning services in China: unintended pregnancy among unmarried graduate students
}

Yuanzhong Zhou ${ }^{1}$, Chengliang Xiong ${ }^{2 *}$, Jinwen Xiong ${ }^{3}$, Xuejun Shang ${ }^{4}$, Guohui Liu ${ }^{5}$, Meimei Zhang ${ }^{6}$ and Pin Yin ${ }^{7}$

\begin{abstract}
Background: Status of premarital sex, unintended pregnancy and associated factors among Chinese graduate students remain unclear. And unmarried graduate students' needs of family planning services seem to be ignored. In the present study, we ascertained the prevalence rate of premarital sex and unintended pregnancy, as well as estimated the possible factors associated with unintended pregnancy among unmarried Chinese graduate students, and evaluated their reproductive health needs.
\end{abstract}

Methods: We obtained the representative sample of graduate students using a multistage, stratified, cluster design, and collected data using a questionnaire.

Results: We obtained 11936 responders. Premarital sexual intercourse was acknowledged by $24.2 \%$ of responders; unintended pregnancy was acknowledged by $4.8 \%$ of responders (19.8\% of students active in premarital sex); and abortion was acknowledged by $4.6 \%$ of responders ( $96.7 \%$ of pregnant students). In multivariate analysis, the identified risk factors for unintended pregnancy among both genders that were active in premarital sex were: (1) having no steady lover [for males: odds ratio (OR), 1.96, 95\% confidence interval (Cl), 1.41-2.70; for females: OR, 2.65; 95\%Cl, 1.56-4.84]; (2) younger age at the first sexual intercourse (for males: OR, 1.62, 95\% Cl, 1.22-2.15; for females: $\mathrm{OR}, 2.57 ; 95 \% \mathrm{Cl}, 1.64-4.02)$; (3) lack of condom use at the first sex (for males: $\mathrm{OR}, 1.13,95 \% \mathrm{Cl}, 1.09-1.37$; for females: $\mathrm{OR}, 2.81$; $95 \% \mathrm{Cl}, 1.81-4.39$ ); (4) unaware of the conditions of conception (for males: OR, 1.69, 95\% Cl, 1.31-2.19; for females: $\mathrm{OR}, 1.75 ; 95 \% \mathrm{Cl}, 1.16-2.65)$; and (5) unaware that abortion endangers women's future pregnancy (for males: OR, 2.98, 95\% Cl, 2.15-4.14; for females: OR, 2.34; 95\% Cl, 1.23-4.46). Medical graduates were not less likely to have unintended pregnancy than nonmedical graduates for both genders.

Conclusions: The avoidable risk of being unintended pregnancy among graduate students in China indicates that an urgent need to take action on how to delay the age of first sex, promote condom use at first sex, and acquire accurate contraceptive information, as well as improve skills to use reliable contraception among graduate students.

Keywords: Education, Graduate, Contraception, Unplanned pregnancy, Universities, Family planning services, China

\section{Background}

Since China has been committed to the reform and opening-up policy to the world, premarital and extramarital sexual intercourse have been more common among young people in China [1-5]. With the growing incidence of premarital and extramarital sex in young people, unintended pregnancy and abortion have be-

\footnotetext{
*Correspondence: clxiong951@sina.com

${ }^{2}$ Institute of Family Planning, Tongji Medical College, Huazhong University of Science and Technology, Hangkong Road 13, Wuhan 430030, China Full list of author information is available at the end of the article
}

come seriously social and health issues in the country [6-8]. Due to China traditional idea of chastity and shortage of educational resources, Chinese young people, in contrast to their western counterparts, do not receive sufficient education of contraception, which often leads to misconceptions with reproduction and contraception $[9,10]$.

China's one child policy was introduced in 1979. It has been practiced to raise living standards by controlling family size and slowing down population growth. It stipulates that a couple should have only one child [11].

\section{Biomed Central}

(c) 2013 Zhou et al.; licensee BioMed Central Ltd. This is an Open Access article distributed under the terms of the Creative Commons Attribution License (http://creativecommons.org/licenses/by/2.0), which permits unrestricted use, distribution, and reproduction in any medium, provided the original work is properly cited. 
As a result, a largest National Family Planning Program in the world has been established in China, and its primary responsibility is to provide family planning services, including contraceptive education, abortion, longacting contraception (e.g. intrauterine contraceptive device (IUD), vasectomy and tubal ligation), and shortacting contraception (e.g. condom, contraceptives) [12]. But some reports showed that services of contraceptive education are still in shortage and that short-acting contraception suitable for persons who have no child are mainly aimed at married persons or at women that are going to have premarital examinations [7,13,14]. Therefore, many unmarried young people did not know where or how to obtain contraception 10 years ago [15]. And, as yet some unmarried youth do not know what are reliable contraception, how to access and use reliable and free contraception [16,17]. Furthermore, lack of counseling and privacy in these services prevents many unmarried people from seeking contraception services [5].

Up to now, China has more than 1.4 million graduate students [18]. Most graduate students are over the legal age for marriage. However, few graduates in China choose to marry their lovers during studies due to the pressure of employment and learning [19]. As a result, they have a longer period between their initiation of sexual activity and marriage than their out-of-school counterparts [19]. On the other hand, it is believed that people with higher education know more contraceptive knowledge [20-22]. Whether the delay of marriage can result in the increase of premarital sex among graduate students, whether they can prevent themselves from unintended pregnancy and abortion more effectively, and whether family planning services can meet their need remain to be clarified.

A section-crossing study was conducted on premarital sexual intercourse and unintended pregnancy among graduate students in different regions from 2007 to 2008. The goal is to ascertain the prevalence rate of premarital sex and unintended pregnancy, to assess possible risk factors of pregnancy for graduate students active in premarital sex, and to obtain background information for further family planning services and contraceptive education.

\section{Methods}

\section{Study setting}

From September 15, 2007 to January 15, 2008, a crosssectional descriptive study was conducted in 49 colleges/ universities in 7 cities of China, including 12 universities in North China (6 in Beijing and 6 in Changchun), 16 in West China (8 in Chongqing and 8 in Chengdu), 7 in East China (7 in Nanjing), 7 in South China (7 in Nanning), and 7 in Central China (7 in Wuhan).

\section{Sampling}

A multistage, stratified, cluster sampling was recruited. Firstly, purposive sampling was used to select city from North, West, East, South and Central of China, respectively. Then, stratified random sampling was used to choose college/university: (a) universities/colleges were divided into four layers (comprehensive, science and engineering, literature and history, and medical); (b) two universities/colleges were randomly sampled from each layer(all schools were selected if the number of schools of this layer less than or equal to 2). In the third stage, stratified cluster sampling was used to select class: (a) classes were divided into two layers (doctoral candidate and master candidate); (b) six classes of master candidate were randomly sampled from university/ college that only has master's degree authorization; six classes of master candidate and two classes of doctoral candidate were randomly sampled from university/ college that have both master's degree and doctoral' degree authorization); (c) all unmarried graduate students (the marriage status was recorded in school) in these chosen classes were recruited, which based on ethical guidelines.

As a result, 13,544 voluntary participants were recruited from 327 classes of 49 universities/colleges of 7 cities. Among them, $88.1 \%(11,936)$ responded validly and completely. Only those who met the description of the corresponding questions were included in analysis. The sample of graduate students active in premarital sex was composed of 1831 males and 1059 females.

\section{Ethics issue}

The topic was an observational study. The ethical issues of Informed Consent and Privacy were fully considered (all students from particular classes were informed by their instructors for the aim of the survey, and students' participation was voluntary and confidential. Each participant signed the informed consent form before the survey. The self-administered questionnaires were distributed among students in classroom with members of the research team present only at the completion of the questionnaire. All answer sheets were made anonymous and tagged by arbitrary codes). The ethics committee of Institute of Family Planning, Tongji Medical College, Huazhong University of Science and Technology reviewed, and voted to approve the study (No. 2007-012).

\section{Questionnaire survey and data collection}

The self-completed questionnaire was designed after a thorough review of similarly published reports. Pilot tests on a group of 800 undergraduates from various grades, disciplines, both genders were randomly selected in Wuhan to determine whether the concepts and expressions used in the questionnaire could be easily 
comprehended. The modified questionnaire consisted of an introduction, personal basic information (gender, age, educational level, discipline and whether having a steady lover), and 48 items covering three topics: (1) awareness of contraception, pregnancy and abortion; (2) attitudes towards abortion; and (3) practices of contraception, pregnancy and abortion. The self-administered questionnaires were distributed among students in classroom then collected locus in quo in 30 minutes.

\section{Data analysis}

Questionnaire data was proofread and entered in EPIdata (version 3.02), and was analyzed using Statistical Package for Social Sciences (SPSS version 12.0). Factors associated with pregnancy among female graduate students/male students' partners were determined in univariate analyses, and were categorized and listed below: (1) basic personal information (educational levels, disciplines, whether having a steady lover, disposable income per month and age at the first sexual intercourse); (2) awareness of contraception (whether knowing the conditions of conception, whether knowing the use of the menstrual cycle for contraception); (3) attitudes towards abortion (whether approving that abortion endangers women's physical and mental health, and future pregnancy); and (4) practices of contraception (whether using contraceptives at the first sexual intercourse, Whether use of condoms at first sexual intercourse, and frequency of use of contraception).

Variables significant in the univariate analyses $(\mathrm{p}<0.05)$ were then entered into a multivariate logistic regression model using forward stepwise logistic regression.

\section{Results}

\section{Characteristics of the study participants}

A total of 11,936 graduate students provided valid answer sheets that supplied details of gender, discipline, and contained responses to more than $90 \%$ of the questions. Among them, 49.4\% was male; $21.9 \%$ was medical student; $12.5 \%$ was doctoral candidate; and up to $70.1 \%$ of responders reported having a steady lover. Their average disposable income per month was 727.2 Yuan; and their average age was 29.4 years (Table 1 ).

\section{Prevalence of pregnancy and abortion}

A history with unintended pregnancy was reported by $3.1 \%$ of females $(17.9 \%$ (190/1059) of females active in premarital sex). Having a partner with pregnancy history was reported by $6.5 \%$ of males $(20.8 \%$ (381/1831) of males active in premarital sex). A history with abortion was reported by $3.1 \%$ of females (97.9\% (186/190) of pregnant females). Having a partner with abortion history was reported by $6.2 \%$ of males $(96.1 \%(366 / 381)$ of males having partners with pregnancy history) (Table 2).

\section{Characteristics of students active in premarital sex}

Among the students active in premarital sex, $88.3 \%$ of males and $92.4 \%$ of females reported that they had a steady lover. $18.9 \%$ of males and $11.1 \%$ of females were less than 20 years old at their first sexual intercourse. $75.6 \%$ of males and $80.4 \%$ of females knew the conditions of conception. $59.4 \%$ of males and $75.6 \%$ of females knew the use of menstrual cycle for contraception. $79.3 \%$ of males and $85.5 \%$ of females agreed that abortion endangers women's physical and mental health. $89.8 \%$ of males and $95.1 \%$ of females agreed that abortion endangers women's future pregnancy. $36.9 \%$ of males and $30.4 \%$ of females used condoms in their first sexual intercourse. $29.9 \%$ of males and $33.8 \%$ of females always used contraception in sexual intercourses (Table 3).

Table 1 Sociodemographic characteristics of unmarried graduate students

\begin{tabular}{|c|c|c|c|c|c|c|}
\hline & \multicolumn{2}{|c|}{ Male(n=5900) } & \multicolumn{2}{|c|}{ Female $(n=6036)$} & \multicolumn{2}{|c|}{ Total $(n=11936)$} \\
\hline & $\mathbf{n}$ & $\%$ & $\mathrm{n}$ & $\%$ & $\mathrm{n}$ & $\%$ \\
\hline \multicolumn{7}{|l|}{ Educational level } \\
\hline Doctoral candidate & 852 & 14.4 & 641 & 10.6 & 1493 & 12.5 \\
\hline Master candidate & 5048 & 85.6 & 5395 & 89.4 & 10443 & 87.5 \\
\hline \multicolumn{7}{|l|}{ Discipline } \\
\hline Medical & 1255 & 21.3 & 1357 & 22.5 & 2612 & 21.9 \\
\hline Nonmedical & 4645 & 78.7 & 4679 & 77.5 & 9324 & 78.1 \\
\hline \multicolumn{7}{|l|}{ Having a stead lover } \\
\hline Yes & 4130 & 70.0 & 4235 & 70.2 & 8365 & 70.1 \\
\hline No & 1770 & 30.0 & 1801 & 29.8 & 3571 & 29.9 \\
\hline Disposable income per month(Yuan, $\bar{x} \pm s)$ & \multicolumn{2}{|c|}{$734.0 \pm 372.8$} & \multicolumn{2}{|c|}{$720.6 \pm 344.6$} & \multicolumn{2}{|c|}{$727.2 \pm 358.8$} \\
\hline$\overline{\text { Age }(\text { year, } \bar{x} \pm s)}$ & \multicolumn{2}{|c|}{$29.6 \pm 3.9$} & \multicolumn{2}{|c|}{$29.2 \pm 4.2$} & \multicolumn{2}{|c|}{$29.4 \pm 4.1$} \\
\hline
\end{tabular}


Table 2 Practice for unintended pregnancy among unmarried graduate students

\begin{tabular}{|c|c|c|c|c|c|}
\hline \multicolumn{2}{|c|}{ Male $(n=5900)$} & \multicolumn{2}{|c|}{ Female $(n=6036)$} & \multicolumn{2}{|c|}{ Total $(n=11936)$} \\
\hline $\mathrm{n}$ & $\%$ & $\mathrm{n}$ & $\%$ & $\mathrm{n}$ & $\%$ \\
\hline
\end{tabular}

History of premarital sexual intercourse (have you experienced at least one times premarital sexual intercourse?)

\begin{tabular}{lllllll}
\hline Yes & 1831 & 31.0 & 1059 & 17.5 & 2890 & 24.2 \\
\hline No & 4069 & 69.0 & 4977 & 82.5 & 9046 & 75.8 \\
\hline
\end{tabular}

History of unintended pregnancy(have(has) you(your partner) experienced at least one times pregnancy?)

\begin{tabular}{ccccccc}
\hline Yes & 381 & 6.5 & 190 & 3.1 & 571 & 4.8 \\
\hline No & 5519 & 93.5 & 5846 & 96.9 & 11365 & 95.2 \\
\hline
\end{tabular}

History of abortion(have(has) you(your partner) experienced at least one times abortion?)

\begin{tabular}{ccccccc}
\hline Yes & 366 & 6.2 & 186 & 3.1 & 552 & 4.6 \\
\hline No & 5534 & 93.8 & 5850 & 96.9 & 11384 & 95.4 \\
\hline
\end{tabular}

\section{Univariate correlation of pregnancy among sexually active students}

In the univariate analyses, (1) having no steady lover (VS. yes), (2) initiating sex before 20 years old (vs. initiating after 20 years old), (3) unawareness of the conditions of conception (VS. awareness), (4) no using condoms in the first sexual intercourse (VS. using), (5) unawareness of the menstrual cycle for contraception (VS. awareness), (6) unawareness of that abortion endangers women's physical and mental health (VS. awareness), and (7) unawareness of that abortion endangers women's future pregnancy (VS. awareness) were related to unintended pregnancy among both females and males' partners. For female graduates, being doctoral candidate (VS. being master candidate), having disposable income less than 400 Yuan per month (VS. having disposable income between 400 and 900 Yuan per month), and no using contraception in their sexual intercourse (VS. always using) suggest more likelihood of reporting unintended pregnancy. Medical graduates were not less likely to have unintended pregnancy than nonmedical graduates for both genders (Table 3 ).

\section{Multivariate correlation of pregnancy among sexually active students}

In the multivariate logistic regression analysis, (1) having no steady lover [male: odds ratio (OR), 1.96; 95\% confidence interval (CI), 1.41-2.70. female: OR, 2.65; 95\% CI, 1.56-4.84], (2) younger age in the first sexual intercourse (male: OR, 1.62; 95\% CI, 1.22-2.15. female: OR, 2.57; 95\% CI, 1.64-4.02), (3) lack of condom use in the first sex (male: OR, 1.13; 95\% CI, 1.09-1.37. female: OR, 2.81; 95\% CI, 1.81-4.39), (4) unawareness of the conditions of conception (male: OR, 1.69; 95\% CI, 1.31-2.19. female: OR, 1.75; 95\% CI, 1.16-2.65), and (5) unawareness of that abortion endangers women's future pregnancy (male: OR, 2.98; 95\% CI, 2.15-4.14. female: OR, 2.34; 95\% CI, 1.23-4.46) were the risk factors for unintended pregnancy for both genders. (Table 4).

\section{Discussion}

In China, reproductive health care is widely available through National Family Planning services. In the last three decades, China has experienced dramatically social changes associated with rapid economic growth and reform. Traditional attitudes towards unmarried cohabitation and premarital sex have also been changed quickly $[9,13,23]$. More young adults with sexual relationship are not legally married. However, social responses to these changes are slow [7]. The current Family Planning Programme still targets mainly on married couples rather than unmarried young people [24].

We found unmarried graduates' average age was 29.4. It was much higher than the legal age for marriage $(\geq 22$ for male and $\geq 20$ for female) in China. During the long period between their initiation of sexual activity and marriage, $31.0 \%$ of male graduates and $17.5 \%$ of female graduates reported a history of premarital sexual intercourse, which was higher than those among undergraduate students (males: 15.4\% 20.2\%; females: 9.4\% 10.6\%) $[2,4,8]$ and among their out-of school counterparts (males: 20.2\% 21.4\%; females: $7.1 \% \sim 8.7 \%$ ) [14,25]. According to the data, $70.0 \%$ of males and $70.2 \%$ of females had a steady lover. We believed that the real prevalence rate of premarital sexual intercourse was much higher than reported. It seemed that unmarried graduate students also need the family planning services.

The prevalence rate of unintended pregnancy among graduate students active in premarital sex was 19.8\% $(571 / 2890)$. It was lower than undergraduate students $(23.1 \% \sim 31.5 \%)[8,26,27]$ and their out-of school counterparts(50\% 64.2\%) [14,28], which might indicate graduate students could prevent themselves from unintended pregnancy more effectively. But we also found nearly all pregnant graduates $(96.7 \%, 552 / 571)$ chose abortion to end pregnancy, which was much higher than undergraduates (78.7\%) [13] and their out-of school counterparts (25\%) [6]. The possible reasons for this might be as fellows: (a) they had no money to feed a baby. Most of them could only get poor living allowances from schools to feed themselves (graduates' disposable income per month was 727 Yuan; Chinese Per Capita Month Disposable Income of Urban Households was 1315 Yuan and Engel's Coefficient of Urban Households was 37.9\% in 2008 [29]); (b) they had no time to feed a baby. Most of them have to spend all their time studying or looking for jobs. In contrast, their out-of-school counterparts who had premarital pregnancy chose to have prompt marriage in most cases [6]; (c) the sexual relationship was not stable for some graduate students. From these, 
Table 3 Factors for unintended pregnancy among graduate students active in premarital sex

\begin{tabular}{|c|c|c|c|c|c|c|}
\hline \multirow{2}{*}{ Factors } & \multicolumn{3}{|c|}{ Male students $(n=1831)$} & \multicolumn{3}{|c|}{ Female students $(n=1059)$} \\
\hline & Total n (\%) & $I O P^{a}$ n (\%) & $\operatorname{COR}^{b}(95 \% \mathrm{Cl})$ & Total n (\%) & $I^{\prime O P} \mathrm{n}(\%)$ & $\operatorname{COR}^{b}(95 \% \mathrm{Cl})$ \\
\hline \multicolumn{7}{|l|}{ Educational levels } \\
\hline Master candidate & 1467(80.1) & $296(20.2)$ & 1 & 885(83.6) & $148(16.7)$ & 1 \\
\hline Doctoral candidate & 364(19.9) & $77(21.2)$ & $1.06(0.80,1.41)$ & 174(16.4) & $40(23.0)$ & $1.49(1.01,2.22)$ \\
\hline \multicolumn{7}{|l|}{ Discipline } \\
\hline nonmedical & 1434(78.3) & 299(20.9) & 1 & $818(77.2)$ & 137(16.7) & 1 \\
\hline medical & $397(21.7)$ & 74(18.6) & $0.87(0.66,1.15)$ & $241(22.8)$ & $51(21.2)$ & $1.33(0.93,1.91)$ \\
\hline \multicolumn{7}{|c|}{ Whether having a steady lover } \\
\hline Yes & 1616(88.3) & $302(18.7)$ & 1 & 979(92.4) & 156(15.9) & 1 \\
\hline No & 215(11.7) & $71(33.0)$ & $2.13(1.56,2.94)$ & $80(7.6)$ & $32(40.0)$ & $3.57(2.17,5.56)$ \\
\hline \multicolumn{7}{|c|}{ Disposable income per month } \\
\hline$<400$ (yuan) & $360(19.7)$ & $79(21.9)$ & $1.13(0.86,1.58)$ & 184(17.4) & $47(25.5)$ & $1.90(1.26,2.87)$ \\
\hline 400 899 (yuan) & $792(43.3)$ & 154(19.4) & 1 & $503(47.5)$ & $77(15.3)$ & 1 \\
\hline$\geq 900$ (yuan) & $679(37.1)$ & $140(20.6)$ & 1.08(0.83,1.39) & $372(35.1)$ & $64(17.2)$ & $1.15(0.80,1.65)$ \\
\hline \multicolumn{7}{|c|}{ Age at first sexual intercourse } \\
\hline$<20$ years & $346(18.9)$ & $91(26.3)$ & $1.53(1.16,2.00)$ & 118(11.1) & $39(33.1)$ & $2.62(1.72,4.00)$ \\
\hline$\geq 20$ years & 1485(81.1) & 282(19.0) & 1 & $941(88.9)$ & 149(15.8) & 1 \\
\hline \multicolumn{7}{|c|}{ Whether knowing the conditions of conception } \\
\hline $\mathrm{Yes}^{\mathrm{c}}$ & $1384(75.6)$ & 243(17.6) & 1 & $851(80.4)$ & 134(15.7) & 1 \\
\hline No & $447(24.4)$ & $130(29.1)$ & $1.93(1.50,2.46)$ & 208(19.6) & $54(26.0)$ & $1.88(1.31,2.69)$ \\
\hline \multicolumn{7}{|c|}{ Whether knowing the use of the menstrual cycle for contraception } \\
\hline Yes $^{\mathrm{d}}$ & $1087(59.4)$ & $199(18.3)$ & 1 & $801(75.6)$ & $130(16.2)$ & 1 \\
\hline No & $744(40.6)$ & $174(23.4)$ & $1.36(1.08,1.71)$ & 258(24.4) & $58(22.5)$ & $1.50(1.06,2.12)$ \\
\hline \multicolumn{7}{|c|}{ Whether thinking abortion endanger women's physical and mental health } \\
\hline Yes & 1452(79.3) & $280(19.3)$ & 1 & $905(85.5)$ & 148(16.4) & 1 \\
\hline No & $379(20.7)$ & $93(24.5)$ & $1.36(1.04,1.78)$ & $154(14.5)$ & $40(26.0)$ & $1.80(1.20,2.68)$ \\
\hline \multicolumn{7}{|c|}{ Whether thinking abortion endanger women's future pregnancy } \\
\hline Yes & 1645(89.8) & 293(17.8) & 1 & 1007(95.1) & $166(16.5)$ & 1 \\
\hline No & 186(10.2) & $80(43.0)$ & $3.48(2.54,4.78)$ & $52(4.9)$ & $22(42.3)$ & $3.72(2.09,6.62)$ \\
\hline \multicolumn{7}{|c|}{ Whether use of condoms at first sexual intercourse } \\
\hline Yes & 675(36.9) & 119(17.6) & 1 & $322(30.4)$ & $27(8.4)$ & 1 \\
\hline No & 1156(63.1) & $254(22.0)$ & $1.24(1.02,1.51)$ & $737(69.6)$ & 161(21.8) & $3.03(2.00,4.76)$ \\
\hline \multicolumn{7}{|c|}{ Whether use of contraceptives at first sexual intercourse } \\
\hline Yes & 1718(93.8) & $341(19.8)$ & 1 & 964(91.0) & 168(17.4) & 1 \\
\hline No & $113(6.2)$ & $32(28.3)$ & 1.60(0.94,2.44) & 95(9.0) & 20(21.1) & 1.26(0.75,2.13) \\
\hline \multicolumn{7}{|c|}{ Frequency of use of contraception(methods were looked as effective for preventing pregnancy by responders) } \\
\hline Always use & $548(29.9)$ & 105(19.2) & $1.71(0.83,3.55)$ & 358(33.8) & 48(13.4) & $0.40(0.16,0.91)$ \\
\hline Often/sometimes & 1209(66.0) & $259(21.4)$ & $1.97(0.97,4.01)$ & $676(63.8)$ & 133(19.7) & $0.63(0.26,1.53)$ \\
\hline Never use & $74(4.1)$ & $9(12.2)$ & 1 & $25(2.4)$ & $7(28.0)$ & 1 \\
\hline
\end{tabular}

${ }^{a}$ : incidence of pregnancy; ${ }^{b}$ : crude odds ratio; ${ }^{c}$ : students select all correct answers of conditions of conception but no wrong answers from list [detail of information was showed as below: What are the basic conditions for human conception? (Multiple choice) 1, healthy and active sperm can get into the vagina, and remain active force; 2 , healthy and mature egg; 3 , cervical mucus must be appropriate and conducive to sperm survival and penetration; 4 , unobstructed reproductive tract to make the sperm and egg meeting; 5 , sperm and egg must combined and formed a fertilized egg; 6 , fertilized egg reach the uterine cavity timely, and the intrauterine environment is suitable for the growth and development of fertilized egg. 7 , the sex intercourse between male and female. If a student chose answer 1,2,3,4,5 and 6 but no 7,.we considered it as 'knowing the conditions of conception', otherwise 'no']; ': students select right answers of calculating periodic abstinence and select the answer of periodic abstinence being not completely safe for contraception from list. 
Table 4 Factors associated with unintended pregnancy among graduate students active in premarital sex

\begin{tabular}{|c|c|c|}
\hline Factors & $\begin{array}{l}\text { Male students }(n=1831) \\
\qquad \operatorname{AOR}^{\mathrm{a}}(95 \% \mathrm{Cl})\end{array}$ & $\begin{array}{l}\text { Female students }(n=1059) \\
\qquad \operatorname{AOR}^{\mathrm{a}}(95 \% \mathrm{Cl})\end{array}$ \\
\hline \multicolumn{3}{|l|}{ Whether having steady lover } \\
\hline Yes & 1 & 1 \\
\hline No & $1.96(1.41,2.70)$ & $2.65(1.56,4.84)$ \\
\hline \multicolumn{3}{|l|}{ Age in first sexual intercourse } \\
\hline$<20$ years & 1.62(1.22,2.15) & $2.57(1.64,4.02)$ \\
\hline$\geq 20$ years & 1 & 1 \\
\hline \multicolumn{3}{|c|}{ Whether using condoms in first sexual intercourse } \\
\hline Yes & 1 & 1 \\
\hline No & $1.13(1.09,1.37)$ & $2.81(1.81,4.39)$ \\
\hline \multicolumn{3}{|c|}{ Whether knowing the conditions of conception } \\
\hline Yes & 1 & 1 \\
\hline No & $1.69(1.31,2.19)$ & $1.75(1.16,2.65)$ \\
\hline \multicolumn{3}{|c|}{ Whether thinking abortion endanger women's future pregnancy? } \\
\hline Yes & 1 & 1 \\
\hline No & $2.98(2.15,4.14)$ & $2.34(1.23,4.46)$ \\
\hline
\end{tabular}

we believed that the convenient family planning services for graduate students was in demand.

We found students with a steady lover had a significantly lower rate of unintended pregnancy. It might indicate that students with a steady lover were much better in preparation for contraception. In contrast, "one-night -stand" students without a steady lover had difficulty in preparing contraception timely due to the risk of being stigmatized for their searching of contraceptive services [5]. Hence, we believed that convenient contraceptive services offer for them might effectively decrease the rate of unintended pregnancy.

Students having sex at younger ages were more likely to report a history of unintended pregnancy in both genders in our study. We presumed that two factors might be important. The first was that students who initiated sex at early age were lacking in awareness of the risks of pregnancy and utilized contraception less often than late initiators did [30]. The second was that the students with earlier initiation of sexual intercourse would be exposed to the longer periods of the risk of unintended pregnancies [24].

Our data showed both genders that used condom in the first sex had a significantly lower rate of unintended pregnancy. It might be that those who used condoms in the first sex has increased likelihood of subsequent condom use [31]. It was regretted that the rate of condom use in the first sex was only $30.4 \%$ for females' partners and $36.9 \%$ for males. Condoms, OCs, withdrawal and periodic abstinence were considered to be the most common contraceptive methods among unmarried people $[6,8]$. However, the last two methods often led to contraceptive failure [32]. We found that $29.9 \%$ of male graduates and $33.8 \%$ of female graduates always used contraception (methods were looked as effective for preventing pregnancy by responders) in their sexual intercourse. But the behavior could not effectively prevent them from unintended pregnancy. We also noticed that OR for female was $<1$, but OR for male was $>1$ of being pregnant (always use contraception that were looked as effective for preventing pregnancy by responders $V S$ never use). We presumed that one of possible reasons was that selfreported 'use of contraception' was not necessarily reliable method. Another possible factor was that male students had more possible classify experience of unintended pregnancy to contraceptive failure instead of absence of contraception. All of these indicates that how to select and how to use contraception correctly might still confuse graduate students.

Unawareness of the conditions of conception and unawareness of that abortion endangers women's future pregnancy were related to pregnancy for both genders. It indicated that improving the awareness of reproduction and contraception might decrease the prevalence rate of unintended pregnancy among graduate students.

Our current data unexpectedly showed that medical students were not less likely to have unintended pregnancy than nonmedical students. In China, nearly all school and college do not set up reproductive and contraceptive courses. And due to the constrained Chinese traditional concept of chastity, students can not obtain correct contraceptive knowledge from society or family. We presumed that medical graduates might know more about the function and structure of the 
reproductive system than nonmedical graduates, but still lacked the knowledge of how to prevent unintended pregnancy.

Based on the multistage, stratified, cluster design, our sample came from diverse regions of China involving various disciplines and university levels. It could reduce the selection bias and nondifferential misclassification in the greatest possible way. Therefore, we believed our findings could be generalized. However, our study might have some bias: (a) for the sensitive question of premarital sex, no special technique (such as randomized responses) was used in the study, which might lead to underestimated rate of premarital sex; (b) for those male students who were reported unintended pregnancy for their partners, we could not judge whether the unintended pregnancy was caused by themselves or not, particularly for those who did not mention a steady lover; and (c) cause-effect relation could not be established and recall bias could not be avoided due to the crosssectional nature of the study.

\section{Conclusions}

The contraceptive education and family planning services supplied in China are lagging behind the current demands of graduate students; the prevalence rate of unintended pregnancy and abortion among graduate students active in premarital sex is high; and some risk of being unintended pregnancy is avoidable. Therefore, as the main contraceptive education and services provider, the family planning service system is in an urgent need to take action on how to delay the age of first sex, promote condom use at first sex, and acquire accurate contraceptive information, as well as improve skills to use reliable contraception among graduate students.

\section{Competing interests}

The authors declare that they have no competing interests.

\section{Authors' contributions}

CLX, XJS, GHL, MMZ and PY designed the survey. YZZ, JWX, XJS, GHL, MMZ, $P Y$ and CLX contributed by performing the investigation and data collection. YZZ and JWX performed the statistical analysis and articles written. Al authors read and approved the final manuscript.

\section{Acknowledgements}

To the Chinese "11th Five-Year Plan" Supporting Science and Technology Project (No. 2006BAl15B04) which sponsored this research, to the research team, and to the 49 colleges/universities involved for their support and cooperation

\section{Author details}

'School of public health, Zunyi medical college, Dalian Road 201, Zunyi 563000, China. ${ }^{2}$ Institute of Family Planning, Tongji Medical College, Huazhong University of Science and Technology, Hangkong Road 13, Wuhan 430030, China. ${ }^{3}$ Department of O\&G, Hubei Provincial Corps Hospital, Chinese People/s Armed Police Forces, Minzhu Road 475, Wuhan 430061, China. ${ }^{4}$ Department of Andrology, Nanjing General Hospital of Nanjing Military Region, Zhongshan East Road 305, Nanjing 210002, China. ${ }^{5}$ Institute for Population and Family Planning of Chongqing City, Honghuang Road 18, Chongqing 400020, China. ${ }^{6}$ Sexual Health Education Research Center, Capital
Normal University, You An Men Xitoutiao 10, Beijing 100069, China. 7Department of Epidemiology, School of Public Health, Tongji Medical College of Huazhong University of Science and Technology, Hangkong Road 13, Wuhan 400030, China.

Received: 23 March 2012 Accepted: 29 November 2012 Published: 6 March 2013

\section{References}

1. Yan H, Li L, Bi Y, Xu X, Li S, Maddock JE: Family and peer influences on sexual behavior among female college students in Wuhan, China. Women Health 2010, 50(8):767-782.

2. Zhang L, Gao X, Dong Z, Tan Y, Wu Z: Premarital sexual activities among students in a university in Beijing, China. Sex Transm Dis 2002, 29(4):212-215.

3. Cao Y, Zhou X, Wang X, He Q, Lui Z, Yang Y, Ji Y: Sexual knowledge, behaviors, and attitudes of medical students in Kunming, China. Psychol Rep 1998, 82(1):201-202.

4. Chen B, Lu Y, Wang H, Ma Q, Zhao X, Guo J, Hu K, Wang Y, Huang Y, Chen P: Sexual and reproductive health service needs of university/college students: updates from a survey in Shanghai, China. Asian journal of andrology 2008, 10(4):607-615.

5. Zhang L, Jejeebhoy S, Shah IH, Zhang L, Hsia J, Im-em W: Access to contraceptive services among unmarried young people in the north-east of China. Eur J Contracept Reprod Health Care 2004, 9(3):147-154.

6. Che Y, Cleland J: Contraceptive use before and after marriage in Shanghai. Stud Fam Plann 2003, 34(1):44-52.

7. Qian X, Tang S, Garner P: Unintended pregnancy and induced abortion among unmarried women in China: a systematic review. BMC Health Serv Res 2004, 4(1):1.

8. Zhou Y, Zhang M, Wei S, Guan H, Yin P, Ren N, Pang X, Xiong C: Survey on knowledge, attitude, practice related to contraception among college students in Beijing. Zhonghua Liu Xing Bing Xue Za Zhi 2009, 30(7):710-712.

9. Huang J, Bova C, Fennie KP, Rogers A, Williams AB: Knowledge, attitudes, behaviors, and perceptions of risk related to HIV/AIDS among Chinese university students in Hunan, China. AIDS Patient Care STDS 2005, 19(11):769-777.

10. WHO, UNICEF: A picture of health: A review and annotated bibliography of the health of young people in developing countries. Geneva: WHO; 1995.

11. Torjesen I: Chinese would resist having larger families if one child policy was relaxed. BMJ 2010, 340:C1212.

12. Family Planning Technical Service Management Ordinance. http://www. gov.cn/zwgk/2005-05/23/content_262.htm].

13. Zhou Y, Xiong C, Yin P, Shang X, Wei S, Liu H, Liu G, Wang X, Zhang M, Li X, Guan H, Xiao D, Pang X, Ren N, Wang M: Survey of Status and Requirement about Sexual Behavior and Contraception among Unmarried College/University Students in China. Acta Med Univ Sci Technol Huazhong 2009, 38(5):561-570-580.

14. Xiong J, Yin P, Guan H, Pang X, Xiong C: Analysis on contraception status and service requirements of high- income youth in Wuhan. Chinese Journal of Maternal and Child Care 2010, 25(6):785-789.

15. Zheng Z, Zhou Y, Zheng L, Yang Y, Zhao D, Lou C, Zhao S: Sexual behaviour and contraceptive use among unmarried, young women migrant workers in five cities in China. Reprod Health Matters 2001, 9(17):118-127.

16. Chen H, Zhang L, Han Y, Lin T, Song X, Chen G, Zheng X: HIV/AIDS knowledge, contraceptive knowledge, and condom use among unmarried youth in China. AIDS Care. 2012, 24(12): 1550-1558.

17. Liu Z, Zhu M, Dib HH, Li Z, Shi S, Wang Z: RH knowledge and service utilization among unmarried rural-to-urban migrants in three major cities China. BMC Publ Health 2011, 11:74.

18. Chinese Ministry of Education: Chinese Education Statistics in 2009. 2010. http://www.moe.edu.cn/publicfiles/business/htmlfiles/moe/s4960/201012/ 113589.html.

19. Zhou X: On the problem of marriage for the youth with a high educational background: A report on the marriage and the concept of child bearing of the Chinese youth. Journal of China Youth College for Political Sciences 2002, 21(4):21-26.

20. Wang L, Yu J, Li X, Fan Y, Tao G, Zhang H: Analysis of contraceptive knowledge level and influencing factors among reproductive women in 
Shandong province. Chinese Journal of Maternal and Child Care 2007, 22(8):1096-1099.

21. Yin X: Analysis of contraceptive knowledge level and influencing factors among unmarried women. Chinese Journal of Maternal and Child Care 2005, 19(1):55-56.

22. Zhou Y, Han T, Huang L: Knowledge, attitude, and behavior to contraception among child-bearing women. Journal of Nursing Science 2010, 25(4):27-29.

23. Zhang K, Li D, Li H, Beck EJ: Changing sexual attitudes and behaviour in China: implications for the spread of HIV and other sexually transmitted diseases. AIDS care 1999, 11(5):581-589.

24. Ma Q, Ono-Kihara M, Cong L, Xu G, Pan X, Zamani S, Ravari SM, Kihara M: Unintended pregnancy and its risk factors among university students in eastern China. Contraception 2008, 77(2):108-113.

25. Zhao F, Wang L, Guo S, Wu J, Ye S: Investigation on sexual behavior with non-spouse and condom use among reproductive age men and women. Chin J Publ ic Heal th 2006, 22(11):1309-1310.

26. Zhou Y, Xiong J, Li J, Huang S, Shang X, Liu G, Zhang M, Yin P, Wei S, Xiong C: Urgent Need for Contraceptive Education and Services in Chinese Unmarried Undergraduates: A Multi-campus Survey. J Huazhong Univ SCi Technol[Med Sci] 2011, 31(3):342-347.

27. Song Y, Ji CY: Sexual intercourse and high-risk sexual behaviours among a national sample of urban adolescents in China. J Public Health (Oxf) 2010, 32(3):312-321.

28. Ye J, Huang S, Ao G: Premarital sex knowledge and sexual behaviors survey to unmarried working male youths. The Chinese Journal of Human Sexuality 2010, 19(8):32-34-40.

29. National Bureau of Statistics of China: China Statistical Year book in 2009: Per Capita Annual Income and Engel's Coefficient of Urban and Rural Households. 2009. [http://www.stats.gov.cn/tjsj/ndsj/2009/html/J0902e.htm]

30. Bender SS, Kosunen E: Teenage contraceptive use in Iceland: a gender perspective. Public Health Nurs 2005, 22(1):17-26.

31. Shafii T, Stovel K, Davis R, Holmes K: Is condom use habit forming? Condom use at sexual debut and subsequent condom use. Sex Transm Dis 2004, 31(6):366-372.

32. Cheng Y, Gno X, Li Y, Li S, Qu A, Kang B: Repeat induced abortions and contraceptive practices among unmarried young women seeking an abortion in China. Int J Gynaecol Obstet 2004, 87(2):199-202.

doi:10.1186/1471-2458-13-198

Cite this article as: Zhou et al:: A blind area of family planning services in China: unintended pregnancy among unmarried graduate students. BMC Public Health 2013 13:198.

\section{Submit your next manuscript to BioMed Central and take full advantage of:}

- Convenient online submission

- Thorough peer review

- No space constraints or color figure charges

- Immediate publication on acceptance

- Inclusion in PubMed, CAS, Scopus and Google Scholar

- Research which is freely available for redistribution 